\title{
TESTE DE RESISTÊNCIA COM TIRAS E BALÕES DE LÁTEX
}

Ivna Motta Ravanello

Centro Universitário Ritter dos Reis

ivyravanello@gmail.com

Juliana Figueiró Ramiro

Centro Universitário Ritter dos Reis

admin@julianaramiro.com.br
Fabiane Wolff

Centro Universitário Ritter dos Reis

fabiane_wolff@uniritter.edu.br

Anne Anicet

Centro Universitário Ritter dos Reis

anne_anicet@uniritter.edu.br

Luis Fernando Folle

Centro Universitário Ritter dos Reis

luis_folle@uniritter.edu.br

Resumo: O presente artigo busca, a partir do ensaio de tração, quantificar a resistências de balões de látex de três marcas distintas. Considerando a ausência de normas técnicas que regulamentem a produção de balões de látex no mercado brasileiro, o que resulta na falta de informações para os consumidores sobre resistência e durabilidade dos produtos em questão, o objetivo deste ensaio é contrapor três marcas que estão sob o mesmo número de identificação - tamanho 7 - e identificar aspectos em comum e divergentes. Para isso, foram avaliadas as medidas globais dos balões para se verificar se há padronização na fabricação dos mesmos. Os resultados apontaram a necessidade de novos testes e da existência de uma norma técnica que regulamente a produção de balões de látex no Brasil, visto que não há correspondência de padrão entre as marcas. Outro resultado verificado é que a cor do balão não muda as características de resistência do mesmo, mostrando que o problema está na fabricação e não no material dos balões.

Palavras-chave: balões de látex, ensaio de tração, análise de materiais.

Abstract: This article uses tensile tests to quantify the resistance of latex balloons of three different brands. Considering the lack of technical standards governing the production of latex balloons in the Brazilian market, which results in the lack of information available to consumers in relation to the resistance and durability of these products, the objective of this paper is to oppose three brands that are under the same identification number - size 7 - and identify similarities and differences. In order to do so, we evaluated the overall measurements of balloons to check for standardization in their manufacturing. The results show the need for new tests and for the existence of a technical standard that regulates the production of latex balloons in Brazil, since there is no standard among the brands. Another result which was verified, is that the color of the balloon 
does not affect its characteristics of resistance, which shows that the problem relates to the manufacturing and not to the material of balloons.

Keywords: latex balloons, tensile testing, materials analysis.

\section{INTRODUÇÃO}

$\mathrm{Na}$ cultura brasileira, os balões de látex são utilizados como artigos de decoração em eventos e datas comemorativas, como aniversários infantis e adultos. Para o Instituto Nacional de Metrologia, Qualidade e Tecnologia (Inmetro), autarquia federal, vinculada ao Ministério do Desenvolvimento, Indústria e Comércio Exterior, que atua como uma espécie de órgão normativo do Sistema Nacional de Metrologia, Normalização e Qualidade Industrial (Sinmetro), os balões de látex não são artigos de decoração, sendo considerados brinquedos infantis. Por esse motivo devem cumprir as normas de segurança em brinquedos, que, como o próprio nome sugere, são orientações de segurança no manuseio dos balões, não abordando questões de qualidade dos produtos, nem apresentando categorizações descritivas dos mesmos.

Para o Inmetro, balões devem conter na sua embalagem as seguintes advertências: "ATENÇÃO! As crianças podem se asfixiar com um balão vazio ou partes de um balão danificado."; "Os adultos devem encher os balões e supervisionar o uso por crianças menores de 6 anos."; "Descartar imediatamente os balões danificados."

Ensaios servem para observar características de materiais em determinada condição, a partir do estabelecimento de um objetivo. No entanto, esse comportamento deve ser entendido antes mesmo da aplicação. Para isso, foram criados os chamados testes mecânicos, que tem por objetivo se determinar, através de condições controladas, qual é esse comportamento do material. Segundo Callister (2005), o comportamento mecânico de um material reflete a relação entre a sua resposta ou deformação pela aplicação de uma carga ou força.

Ainda para Callister (2005), as propriedades mecânicas dos materiais são verificadas através da realização de experimentos de laboratório cuidadosamente desenhados que replicam o mais próximo possível das condições de serviço. Os fatores a serem considerados incluem a natureza da carga aplicada e a sua duração, assim como as condições ambientais. Propriedades mecânicas são motivo de preocupação para uma variedade de áreas (por exemplo, produtores e consumidores de materiais, organizações de pesquisa, agências governamentais) que têm interesses diferentes. Por conseguinte, é imperativo que haja alguma consistência na forma em que são realizados ensaios e na interpretação dos resultados. Esta consistência é realizada usando técnicas de ensaio normalizados. O estabelecimento e a publicação destas normas são frequentemente coordenado por sociedades profissionais. No Brasil, a organização mais ativa é a Associação Brasileira de Normas Técnicas (ABNT). A ABNT compreende numerosos volumes, que são emitidos e atualizados anualmente; um grande número destas normas se relacionam com técnicas de ensaio mecânico

Ao observar embalagens do produto, que é objeto de estudo deste trabalho, percebe-se que as marcas, possivelmente numa tentativa de melhor se comunicar com 
seus consumidores, criaram categorias para diferenciar os balões. Uma das marcas selecionadas neste ensaio chama a atenção no tamanho, em que a medida é em Polegadas. Contudo, nem todas apresentam tal unidade e balões de marcas diferentes, sob a mesma medida 7 , apresentam medidas em centímetros $(\mathrm{cm})$ diferentes, o que evidencia a falta de uma padronização normativa da produção, que pode ou não impactar no desempenho de uso dos balões. A partir de um ensaio de tração, este artigo busca observar a existência deste impacto.

\section{MÉTODO}

Para a realização dos ensaios foram utilizadas tiras e balões de látex de três marcas diferentes, submetidas a ensaio de tração na máquina Universal de ensaios, marca EMIC, modelo DL10000, com o objetivo de observar a deformação $(\mathrm{mm}) \mathrm{em}$ função da força $(N)$ empregada no processo.

\subsection{Materiais e métodos}

Os materiais utilizados na realização do ensaio foram balões de látex de três marcas diferentes - São Roque, Regina e Joy, comercializadas no mercado brasileiro, além de tiras desses mesmos balões, feitas no sentido vertical e horizontal, como mostra a figura 1. Todos as amostras, antes de serem submetidas ao ensaio, tiveram as seguintes medidas consideradas: o balão inteiro - altura total, largura máxima da gota, largura do bico e espessura e recortes verticais e horizontais. Os ensaios de tração foram feitos no balão inteiro e posteriormente nas tiras recortadas.

As tiras verticais das três marcas de balão foram feitas com as seguintes medidas: $65 \mathrm{~mm}$ de altura e $23 \mathrm{~mm}$ de largura. Já as tiras horizontais ficaram com 46 $\mathrm{mm}$ de altura e $20 \mathrm{~mm}$ de largura.

Figura 1 - Desenho das medidas e cortes realizados na preparação das amostras do ensaio proposto.

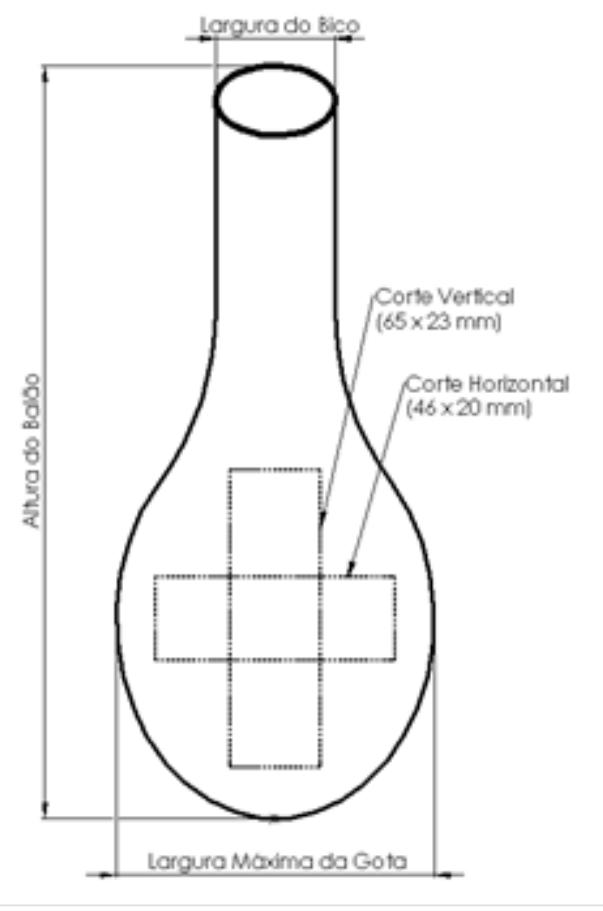

Fonte: Elaborado pelos autores 
Segundo Santos et. al (2009), testes de tração em materiais elásticos servem para observar níveis de resistência dos mesmos. Assim, neste ensaio, foram realizados testes em tiras e balões de látex de três marcas com objetivo de observar o deslocamento $(\mathrm{mm})$ em função da força $(\mathrm{N})$ empregada no processo. Também foram propósitos deste trabalho avaliar, entre as três marcas, qual é a mais resistente.

Todas as amostras, para realização dos testes, foram presas à máquina pelas suas extremidades. Com os balões inteiros, a máquina partiu de uma abertura de 60 $\mathrm{mm}$ entre as garras, e com as tiras verticais e horizontais foram iniciados os testes com a máquina saindo de uma abertura de $30 \mathrm{~mm}$. Todos os ensaios foram finalizados no instante em que a amostra chegou na sua deformação máxima, entendida aqui como a ruptura da mesma.

Foram realizados um total de nove (9) testes com cada uma das marcas dos balões, sendo três (3) ensaios com o balão inteiro, três (3) com uma tira de balão cortada na vertical e três (3) com uma tira de balão cortada na horizontal. Os testes foram feitos com cores diferentes para se avaliar se a cor impacta na resistência do balão. Para a medição da espessura dos balões foi utilizado um Micrômetro Externo Digital Micromaster de 0-30mm, com resolução de 0,001mm.

\subsection{RESULTADOS E DISCUSSÕES}

Os dados de altura total, largura máxima, largura do bico e espessura são apresentados na tabela 1.

Tabela 1 - Medidas geradas dos balões em milímetros.

\begin{tabular}{lllll}
\hline Marca & Altura Total & Largura Máxima & Largura do Bico & Espessura \\
\hline São Roque & 101 & 48 & 21 & 0,290 \\
\hline Regina & 90 & 41 & 24 & 0,213 \\
\hline Joy & 86 & 44 & 20 & 0,196 \\
\hline
\end{tabular}

Fonte: Elaborado pelos autores.

Através dos dados, pode-se observar que as alturas e as larguras dos balões inteiros variam de marca para marca, mesmo todos estando sob o mesmo número 7 que em uma das embalagens indica o símbolo de polegada ("), mas nas outras não apresenta unidade de medida. A medida de 7 polegadas é equivalente a $177,8 \mathrm{~mm}, 0$ que não corresponde a nenhuma das medidas aferidas. Nas demais medidas - largura máxima da gota, largura do bico e espessura verifica-se a mesma falta de padrão.

Os balões da marca São Roque têm maior altura e maior largura máxima da gota, em comparação com as demais marcas. Os balões da marca Regina possuem maior largura do bico. Tais valores são fruto de uma média de medição entre três balões da mesma marca. Sobre essa média, vale frisar que os balões da marca Joy têm medidas muito aproximadas entre eles, porém alguns apresentam deformações visíveis, que foram descartadas das análises.

Nos ensaios de força por deslocamento foram testados primeiramente os balões inteiros e posteriormente os cortes verticais e horizontais. Também foram 
feitos ensaios com cores variadas para se avaliar se a cor influencia nos resultados. As figuras 2, 3 e 4, mostram os balões inteiros ensaiados com cores diferentes.

Figura 2 - Ensaio de tração no balão inteiro da marca São Roque.

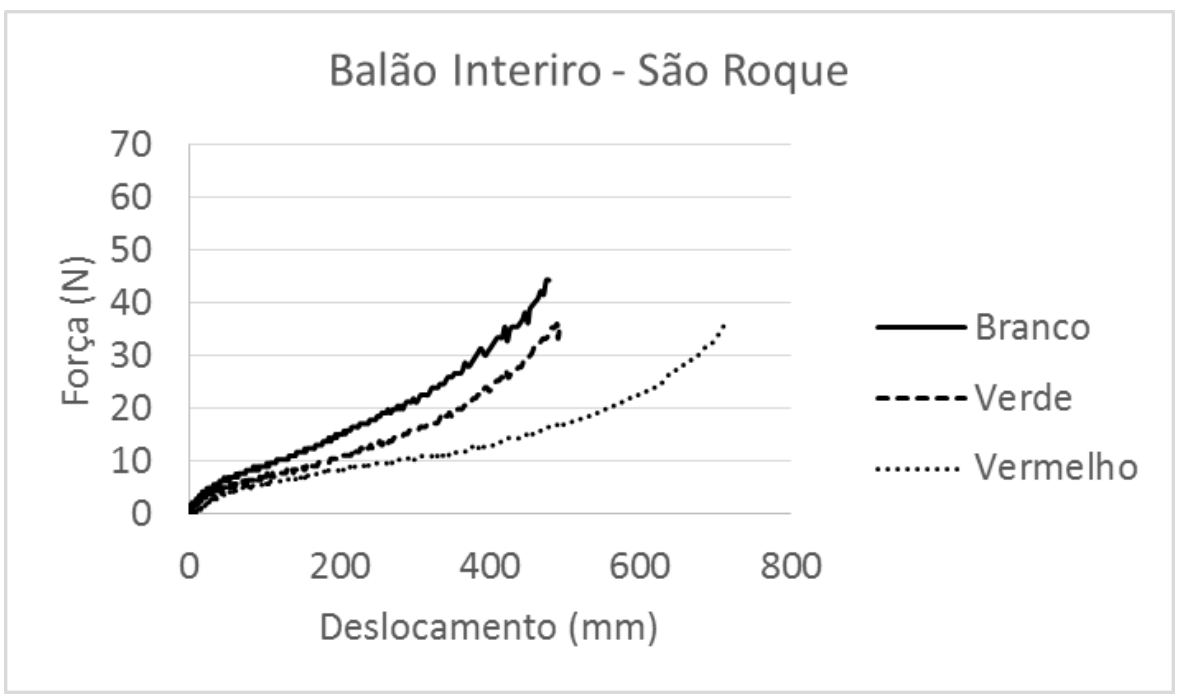

Fonte: Elaborado pelos autores.

Figura 3 - Ensaio de tração no balão inteiro da marca Regina.

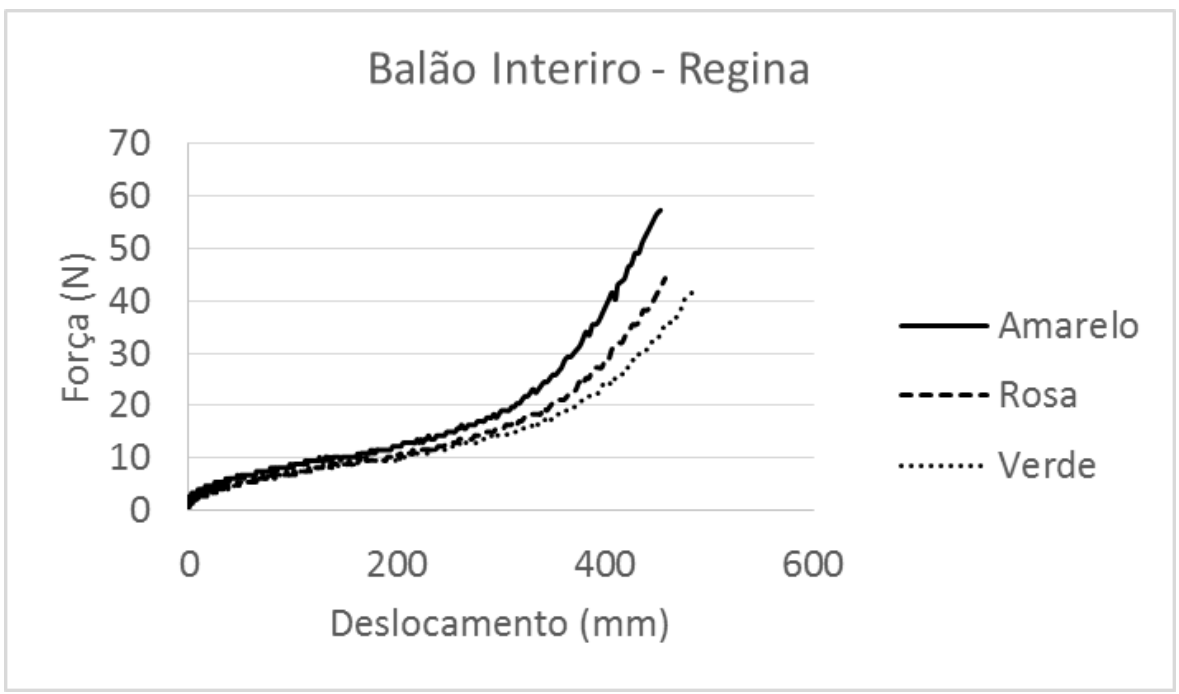

Fonte: Elaborado pelos autores. 
Figura 4 - Ensaio de tração no balão inteiro da marca Joy.

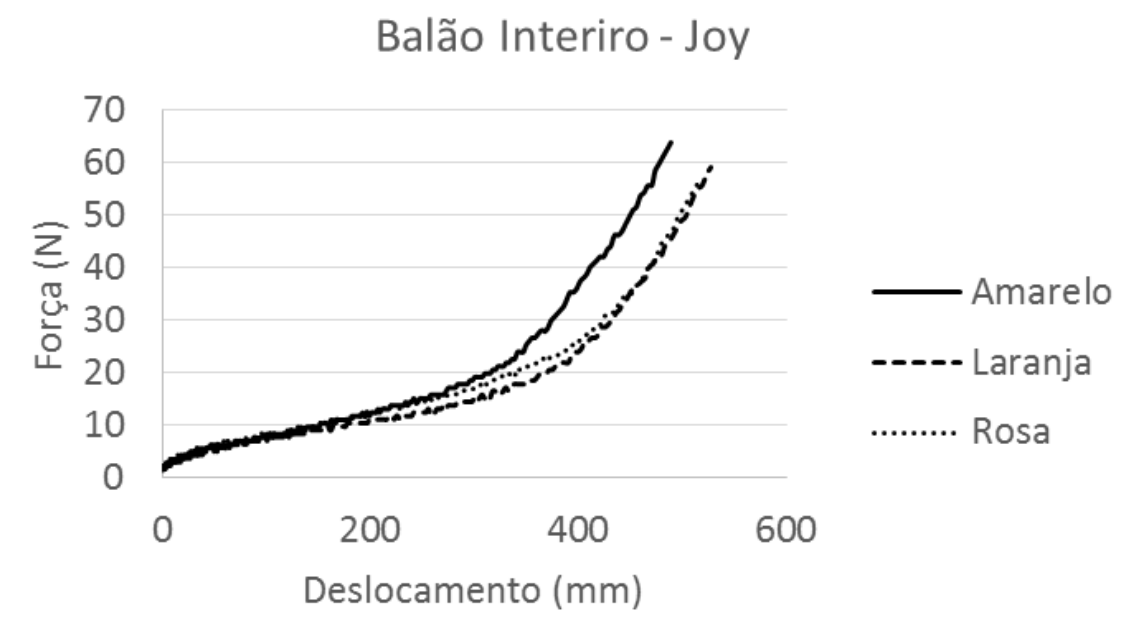

Fonte: Elaborado pelos autores.

Pelos testes é possível identificar que para os balões São Roque, a cor tem uma influência grande, seguido das marcas Regina e Joy. No entanto, os testes com balões inteiros são muito suscetíveis a falhas pois a amostra é irregular, ou seja, tem mais material em uma extremidade do balão que na outra e, consequentemente, uma das extremidades contará com mais material para a garra segurar. Além disso, tem o fato de que os balões não são exatamente iguais, fazendo com que pequenas falhas nas dimensões influenciem nos resultados.

Assim, a hipótese de que a cor pode ou não influenciar nos resultados foi testada com a padronização dos ensaios, ou seja, tirando-se amostras dos balões com as mesmas medidas. $O$ único fator que vai ser diferente entre eles é a espessura do material, como mostrado anteriormente.

Os gráficos das figuras 5 e 6 mostram esses resultados.

Figura 5 - Ensaio de tração das três marcas com corte vertical.

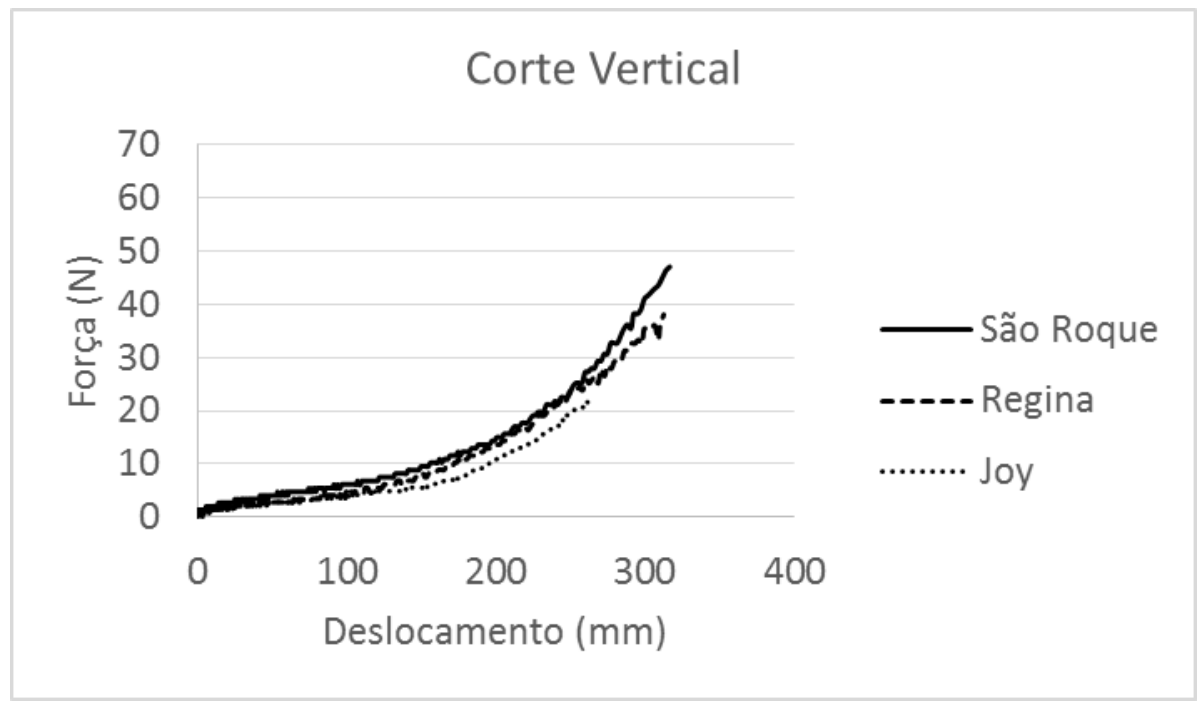

Fonte: Elaborado pelos autores. 
Figura 6 - Ensaio de tração das três marcas com corte horizontal.

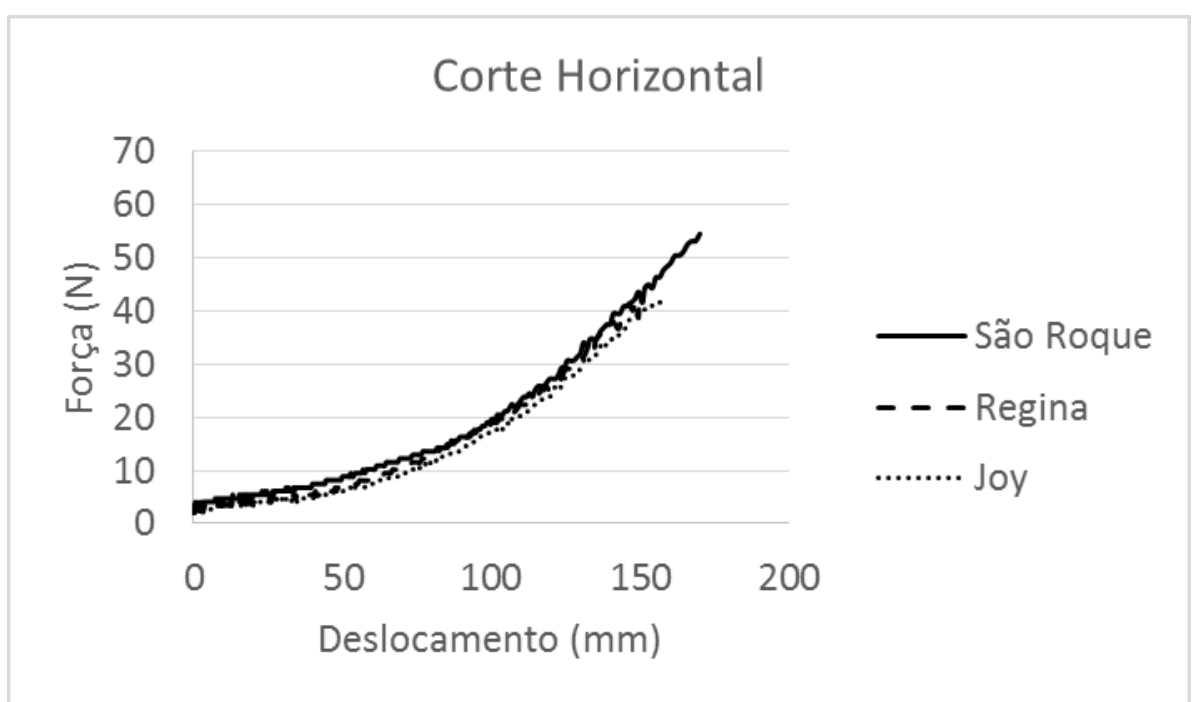

Fonte: Elaborado pelos autores.

É possível notar que independente da marca, as curvas têm praticamente os mesmos resultados. O que faz com que uma curva seja levemente maior que a outra é exatamente a diferença nas espessuras, sendo a São Roque a mais espessa, seguido da Regina e Joy.

Como cada teste foi feito com uma cor diferente, fica claro que a cor não tem influência nos resultados. Assim, a diferença nas curvas das figuras 2,3 e 4 se dá exclusivamente pela falta de padronização na fabricação das marcas, o que justifica os resultados da marca São Roque serem os mais irregulares.

Por fim, a título de comparação, foram plotadas as três marcas com o ensaio do balão inteiro para ver qual a mais resistente. A figura 7 mostra os resultados.

Figura 7 - Ensaio de tração das três marcas com o balão inteiro.

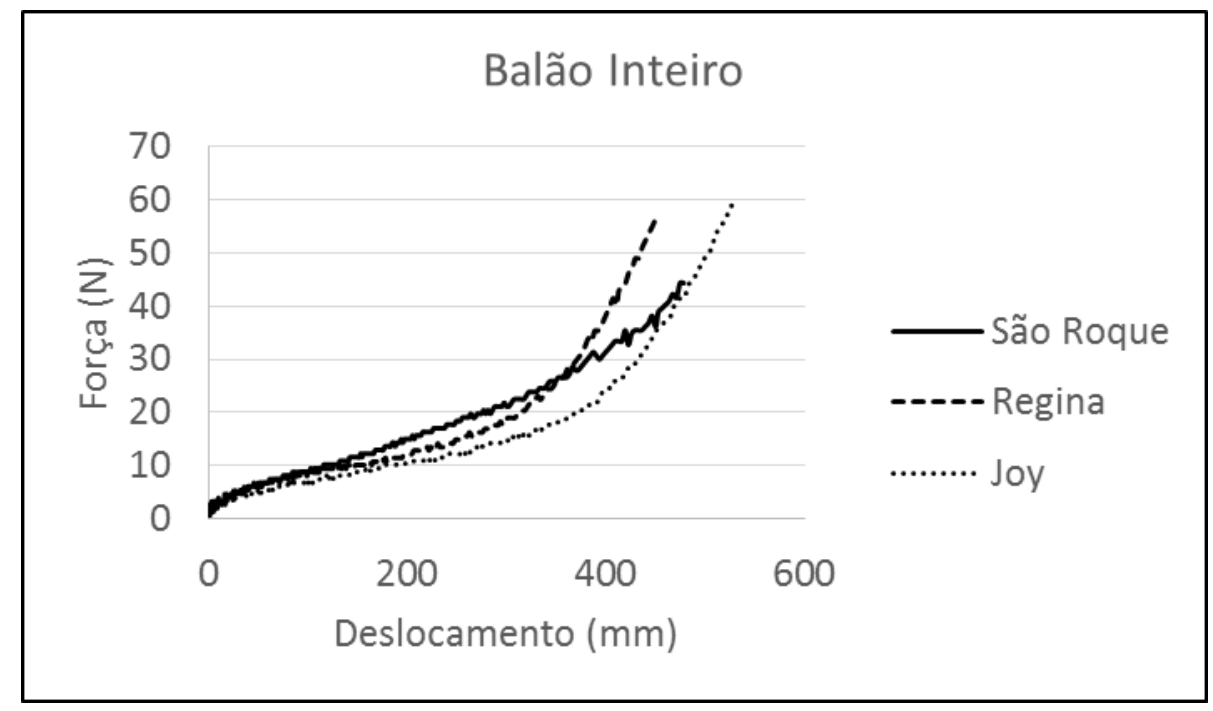

Fonte: Elaborado pelos autores. 
Do ensaio foram selecionadas as curvas de maior resistência de cada marca e, a partir deste recorte, é possível observar que a marca Regina tem maior resistência que a Joy, e que a marca São Roque tem uma região mais resistente e outra que vai abaixo da marca Regina. Isso se deve inicialmente pelo fato de que as marcas têm diferença nas medidas das altura e larguras, assim como na espessura e, também, que a marca São Roque tem pouca padronização, ou seja, os balões dessa marca são muito desiguais entre si nas suas medidas globais.

\section{CONCLUSÕES}

Considerando todos os resultados obtidos nos testes, pode-se afirmar que, embora, de modo geral, os balões São Roque tenham apresentado desempenho inferior, não existe um padrão possível de ser verificado a partir dos parâmetros selecionados para o ensaio. Assim, afirma-se que tais parâmetros não são os principais influenciadores da resistência de um balão.

A partir das medidas de altura, largura máxima da gota, largura do bico e espessura também não se pode identificar um padrão entre os balões. Isso evidencia o fato de que esses produtos estão sob uma mesma unidade de medida - o número 7, porém isso não significa que há uma padronização na fabricação dos mesmos.

Por fim, além de testes e da análise de processos de produção para identificar que parâmetros são os que influenciam diretamente na resistência de balões, os autores sugerem o desenvolvimento de uma norma técnica para esses produtos, onde seria descrita a escala de variação das medidas de determinado balão, submetido a determinada classe de medida. Ainda, a partir da norma seriam regulamentados os testes de desempenho, que para além da pesquisa científica, serviriam para melhor orientar os consumidores desse produto.

\section{REFERÊNCIAS}

BRASIL. INMETRO. Regulamento Técnico da Qualidade para BRINQUEDOS. 2014. Disponível em:

<http://www.inmetro.gov.br/barreirastecnicas/pontofocal/textos/regulamentos/BRA_ 597.pdf>. Acesso em: 15 dez. 2015.

CALLISTER, William D. Fundamentals of materials science and engineering: an integrated approach. [S.I.]: J. Wiley, 2005. 124 p.

EQUIPAMENTOS PARA ENSAIOS MECÂNICOS DESTRUTIVOS (Org.). SÉRIE 23 EMIC (TRAÇÃO, COMPRESSÃO, FLEXÃO, ETC). Disponível em:

<http://www.emic.com.br/Produtos+Mais/4/77>. Acesso em: 15 dez. 2015.

GASPERI, Graziela de et. al. Avaliação mecânica da resistência de faixas elásticas. Revista Brasileira de Fisioterapia. [online] 2009, 13 (Novembro-Dezembro). Disponível em: <http://redalyc.org/articulo.oa?id=235016472007> ISSN 1413-3555. Acesso em 15 de dezembro de 2015. 